zantherin A 0,021-0,024, shizandrin A 0,017-0,019, shizandrin B 0,074-0,095. Total content of shizandrins calculated in shizandrol A equivalents was about $0.3 \%$. Relations between individual lignans were about 1:1:0,2:0,2:1. This is optimal for adaptogenic properties of Shizandra drugs (2). Thus, fatty oils are effective for shizandra lignans extraction. The method was proposed for extract standardiza- tion and validated according to the $\mathrm{ICH}$ guidelines on the validation of analytical methods and (3).

References: (1) Shikov A. N., Pharm.Chem. J., 2006, 29: 385-388. (2) Panossian A., Wikman G.J., Ethnopharmacol., 2008, 118: 183212. (3) USP 32/NF 27. Validation of compendial procedures, 2009: 733-735.

\title{
ANTIDIABETIC EFFECT OF UBIDECARENONE IN RATS
}

\section{() Kovaleva M. A., Kokareva M. N., Makarova M. N., Makarov V. G.}

\section{Saint-Petersburg Institute of Pharmacy, Russia}

Diabetes mellitus is characterized by hyperglycemia, altered metabolism of lipids, carbohydrates and protein and an increased risk of complication of vascular diseases. Type 2 diabetes mellitus is characterized by derangement of insulin secretion and an inability of the peripheral tissues to respond to insulin. Antioxidant often been used for the treatment of diabetes and its complications. The purpose of the study was evaluation of antidiabetic activity of ubidecarenone, in the model of neonatal streptozotocin-induced diabetes on rats. Experiment was performed on rats-males and rats-female Wistar line. Diabetes was induced by a single dose intraperitoneally injection of streptozotocin $(60 \mathrm{mg} / \mathrm{kg})$ at 3 days postnatal. After 4 weeks the rats were orally administrated with ubidecarinon in starch slime at dose of $5.2 \mathrm{mg} / \mathrm{kg}$ (UC group); or starch slime (control group). Levels of glucose, body weight, total cholesterol, triglycerides were evaluated during the experiment. The ubidecarinone showed steady antidiabetic effect after
4 weeks of administration. Decrease level of blood glucose in $50 \%$ (rats-males) and $41 \%$ (rats- female) was obserwed. Results are present in the table:

\begin{tabular}{|l|c|c|}
\hline \multirow{2}{*}{ Group } & \multicolumn{2}{|c|}{ Blood glucose, mmol/l } \\
\cline { 2 - 3 } & Base line & After 4 weeks \\
\hline rats-males & $13,2 \pm 0,9$ \\
\hline Control $(n=6)$ & $12,8 \pm 1,1$ & $6,6 \pm 0,2^{*}$ \\
\hline UC $(n=6)$ & $11,6 \pm 1,3$ & $11,4 \pm 0,8$ \\
\hline rats- female & $9,4 \pm 0,7$ & $6,7 \pm 0,3^{*}$ \\
\hline Control $(n=6)$ & $10,7 \pm 0,9$ & \\
\hline UC $(n=6)$ & \multicolumn{3}{|c|}{$(p<0.05)$} \\
\hline *- significantly different from control group
\end{tabular}

Ubidecarinone effectively normalized metabolism in animals that was conformed by increased of glucose recycling by peripheral fabrics and displayed cytoprotective effect. Experiment data allow us to recommend ubidecarinone for further study, including clinical.

\section{THE APPROACH TO AN ANALYSIS OF TRACE ELEMENT STRUCTURE OF PLANTS}

\section{(C) Kruglov D. S.}

Novosibirsk State Medical University, Russia

Nowadays a lot researches are devoted to studying of herbs as sources of the essential trace elements. The number of elements defined by means of modern methods of masspectrometry, reaches 70 . There are two methods, which are used more often in the analysis of the amount of microelements. The first method is comparing of the elements which are contained in objects in extreme quantities. The second method is the establishment of the pair correlations between the separate elements. Both of these methods do not appear informative enough. The means of a data clustering have been applied which allow to analyze the set of all experimental data simultaneously. One of the most widely-used classes of methods involves hierarchical agglomerative clustering, in which two groups, chosen to optimize some criterion, are merged at each stage of the algorithm. The Ward's method was taken as a rule for association or communication of two groups into one cluster. The sum of root-mean-square deviations for any two (hypothetical) clusters which can be generated on each step must be minimized by this method. The distance between different clusters must be not less than a limit of variability of amount of the trace element the value of which was taken as $10 \%$. The aim of this work is the making of method which can be used for analysis of a lot data about con- 
tent of trace elements. The aerial parts of 55 different plants of family Boraginaceae, which were collected on the Eurasian continent, were used as the research objects. Besides, various parts of plants of genus Pulmonaria which possessed the different pharmacological activity were used as objects of research too. The amount of the trace elements in the researched object was determined by means of inductively-coupled plasma mass spectroscopy. It was determined the content of 59 elements. As a result it was estab- lished that the dividing of elements into clusters in a hierarchical tree correlates with the systematic position of plants (factor of correlation 0,92). Besides, the dividing of elements into clusters for various parts of Pulmonaria correlates with pharmacological activity of the phytomedicines which were made from these parts. Thus, the offered method of the analysis of the trace element structure of a plant allows more effectively looking up the new plants which will be sources of the essential elements.

\section{PHENOLIC COMPOUNDS OF PULMONARIA MOLLIS}

\section{(C) Kruglov D. S. ${ }^{1}$, Fursa N. S. ${ }^{2}$}

${ }^{1}$ Novosibirsk State Medical University, Russia

${ }^{2}$ Yaroslavl State Medical Academy, Russia

The development cycle of Pulmonaria mollis Wulf ex Hornem can be divided into 2 periods - the first one is a short period from germination to the end of the fruiting stage, during which the floriferous shoots are developing; and the second one is a long period during which the root leaves are growing from underground resting buds. The medicines made from floriferous shoots have an antianemic activity. At the same time, the medicines made from the root leaves have expectorant activity. The aim of work is the characterization of phenol compounds of these parts of the plant. The floriferous shoots and the root leaves were collected in the Novosibirsk region. The raw materials were dried before analysis. The amount of phenolic compounds was measured by means of HPLC. Identification of components was done by comparison with the standard substances.

For the first time dihydroquercetin was discovered among the phenolic compounds of floriferous shoots, and vicenin in the root leaves. It is noteworthy that dihydroquercetin possesses strong anti-hemorrhagic action while vicenin has mainly an expectorant action. Thus, the various pharmacological activities of medicines made from theinvestigated plant parts of $P$. mollis could be connected with the different contents of phenolic compounds.
Table. The content of phenol compounds in different parts of P.mollis

\begin{tabular}{|l|c|c|}
\hline \multirow{2}{*}{ Compound } & \multicolumn{2}{|c|}{ Relative amount, \% } \\
\cline { 2 - 3 } & floriferous shoots & root leaves \\
\hline Gallic acid & 20,6 & 24,23 \\
\hline Catechin & 2,22 & 1,8 \\
\hline Chlorogenic acid & 3,75 & 0,94 \\
\hline Neochlorogenic acid & 2,58 & 2,97 \\
\hline Caffeic acid & 3,94 & $-* 1$ \\
\hline Cichoric acid & - & 3,4 \\
\hline Ferulic acid & 22,5 & - \\
\hline Vicenin & - & 1,79 \\
\hline Dihydroquercetin & 8,11 & - \\
\hline Kaempferol & 1,46 & - \\
\hline Luteolin 7-glucoside & - & 1,16 \\
\hline Apigenin & - & 0,18 \\
\hline$\star 1-$ it is not revealed & & \\
\hline
\end{tabular}

